\title{
CORRECTION
}

\section{Correction to: Bariatric efficiency at an academic tertiary care center}

\author{
Wanda Lam ${ }^{1} \cdot$ Gi Yoon Kim ${ }^{1} \cdot$ Clayton Petro ${ }^{1}$ - Adel Alhaj Saleh ${ }^{1} \cdot$ Leena Khaitan $^{1}$
}

Published online: 16 April 2020

(c) Springer Science+Business Media, LLC, part of Springer Nature 2020

\section{Correction to: Surgical Endoscopy}

https://doi.org/10.1007/s00464-020-07507-6

This article was updated to correct Adel Alhaj Saleh's name, incorrectly displayed as Adel A. Saleh.

It is correct as displayed here: Adel (first name) Alhaj Saleh (last name).

Publisher's Note Springer Nature remains neutral with regard to jurisdictional claims in published maps and institutional affiliations.

The original article can be found online at https://doi.org/10.1007/ s00464-020-07507-6.

Wanda Lam

wanda.lam@uhhospitals.org

1 Department of Surgery, University Hospitals Cleveland Medical Center, 11000 Euclid Avenue, Lakeside 7th Floor,

Cleveland, $\mathrm{OH} 44106$, USA 